\title{
Initial Leakage Under Pit and Fissure Sealants Assessed by Neutron Activation
}

\author{
J. B. DENNISON, J. M. MEYER,* S. B. BIRNHOLTZ, and R. G. CRAIG \\ School of Dentistry, University of Michigan, Ann Arbor, Michigan 48104, USA
}

An improved neutron activation method and a model system were used to study microleakage associated with three pit and fissure sealants. Both the sealant and the etching procedure were evaluated on enamel surfaces as well as in prepared model pits. Leakage was reduced to 3 to $4 \mu \mathrm{g}$ for all three materials, and the etching process was relatively ineffective in forming an initial seal.

Recently, a great deal of effort has been concentrated in the area of preventive dentistry. Among the many products to evolve from this effort are materials designed to obtund and to seal occlusal pits and fissures from the ingress of saliva and food particles. Topical and systemic fluoride treatments have proven effective in the reduction of smooth surface caries, but have shown little or no effect on pit and fissure surfaces. ${ }^{1}$ On the other hand, autopolymerizing sealant materials gain retention from the pits and fissures into which they are placed, and thus, with proper sealing, are expected to isolate such areas of viable enamel from a cariogenic environment. ${ }^{2-4}$

The objective of this study was to examine the sealing capabilities of three commercially produced pit and fissure sealants with the use of a quantitative technique (neutron activation) and appropriate statistical analysis.

\section{Materials and Methods}

Neutron activation analysis was the analytical technique used for this study of potential leakage around sealant materials, which is based on previously published data.5,6 The activation technique has been standardized to produce reliable results and it is

Received for publication July 20, 1973.

- Present Address: $\mathbf{E}$ cole de Médecine Dentaire, 30, rue Lombard, 1211 Geneva 4, Switzerland. the only leakage technique available that is quantitative. As in the previous work, dysprosium was used as the tracer element.

The factors considered in the design of the experiment are shown in Table 1. Two types of surfaces were selected for study. Polished enamel from the buccal surface of freshly extracted molars was used as one surface to establish a reference value. A model pit was prepared on similar teeth as a test surface to standardize the surface area involved in placing and in evaluation of sealant materials. The preparation was kept as narrow as instrumentation would permit and was carried to a minimal depth within dentin to simulate an occlusal pit but yet to standardize the area to which both etchant and sealant could be applied. Each prepared pit was cut to the diameter and taper of a $169 \mathrm{~L}$ bur and was placed to a depth of $2.5 \mathrm{~mm}$ from the enamel surface (Fig 1).

Three sealant systems were studied under diverse surface conditions. Nuva-Seala is a BIS-GMA resin system, similar to those used for most composite restorative resins, but it contains an activating agent that is sensitive to ultraviolet light. All samples evaluated in this study were polymerized by a 40 second exposure to ultraviolet light from an activation gun provided by the manufacturer. Material 2 is an experimental caries preventative system ${ }^{\mathrm{b}}$ and it is basically an $\alpha$-cyanoacrylate mixed with a silica filler. Epoxylite $9070^{c}$ (material 3) is an autopolymerizing polyurethane resin containing $10 \%$ sodium monofluorophosphate. Both materials 2 and 3 are sensitive to temperature and humidity

a Nuva-Seal, L. D. Caulk Co., Div of Dentsply International, Inc., Milford, Del.

${ }^{b}$ Minnesota Mining and Manufacturing Co., St. Paul, Minn.

c Epoxylite 9070, Lee Pharmaceuticals, South E] Monte, Calif. 
TABLE 1

Experimental Design Factors

\begin{tabular}{lc}
\hline Factor & Levels \\
\hline $\begin{array}{l}\text { Specimen } \\
\text { Enamel surface }\end{array}$ & 2 \\
Artificial pit & \\
Sealant & 3 \\
1, BIS-GMA resin activated by & \\
ultraviolet light & \\
2, $\alpha$-cyanoacrylate & \\
3, polyurethane & \\
Sealing & 2 \\
Unsealed \\
Sealed \\
Etchant \\
1, $\mathrm{H}_{3}$ PO $(50 \%)$ \\
2, $\mathrm{H}_{3}$ PO $(0.05 \mathrm{M})$ \\
3, Citric acid $(50 \%)$ \\
Etching \\
Unetched \\
Etched
\end{tabular}

during setting and samples were, therefore, permitted to set in a humidor at $37 \mathrm{C}$ for 12 hours before testing.

Recommended surface preparation varied for each material, although each was supplied with a specific acid etchant to clean the enamel surface and to facilitate the formation of retention tags. A $50 \%$ solution of phosphoric acid was used with material 1; a $0.05 M(0.5 \%)$ solution of phosphoric acid was used with material 2; and a $50 \%$ solution of citric acid was used in conjunction with material 3. Etchants were applied according to manufacturer's recommendations; etches 1 and 3 were applied for one minute and etch 2 was applied for 30 seconds. The enamel surface and the model pits were evaluated in both etched and unetched and sealed and unsealed conditions, with a basic sample size of three for the enamel and control groups or of six for the model pits in the test groups.

After specific sample preparation according to the experimental design, each sample was waxed, soaked in tracer solution, activated, and counted as described in previous work on the improved neutron activation technique. 6 All teeth were coated with hot utility wax to within $0.5 \mathrm{~mm}$ of the margin of the inserted material or an area of enamel similar in size. Each sample was then soaked for one hour in a solution ( $1 \mathrm{gm} / 100 \mathrm{ml}$ ) of dysprosium nitrate ${ }^{d}\left[\mathrm{Dy}\left(\mathrm{NO}_{3}\right)_{3} \cdot 5 \mathrm{H}_{2} \mathrm{O}\right]$. Teeth were then rinsed, dried, and placed in the core of a nuclear reactore for activation. Irradiation was carried out for one minute at 2 megawatts power in a neutron flux of 2 $\times 10^{13}$ neutrons $/ \mathrm{cm}^{2} / \mathrm{sec}$. A decay period of three minutes was allotted, followed by counting for 40 seconds of live time on a

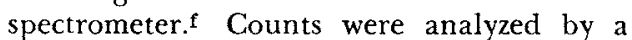
4096 channel analyzer, and the printed data was then applied by computer to a previously described program 6 to obtain uptake values for dysprosium in micrograms per tooth. A standard solution of dysprosium $(100 \mu \mathrm{g})$ and an unexposed tooth blank were irradiated with each group of samples that were run and used as a basis for computing background values and peak selection.

\section{Results}

The results obtained with the different types of surfaces (polished enamel and the model pits), for the various treatments (etched or unetched, sealed or unsealed) and their combinations are grouped in Table 2 according to the nature of the pit and fissure sealant. These results are expressed as the mean uptake of dysprosium tracer in micrograms per tooth, and the coefficient of variation for every group also is given.

d Pfaltz and Bauer, New York, NY.

e Phoenix Memorial Laboratory, University of Michigan, Ann Arbor, Mich.

f Germanium Low Energy Photon Spectrometer, Model 8113-16350, Ortec Inc., Oak Ridge, Tenn.

s Nuclear Data Inc., Palatine, Ill.

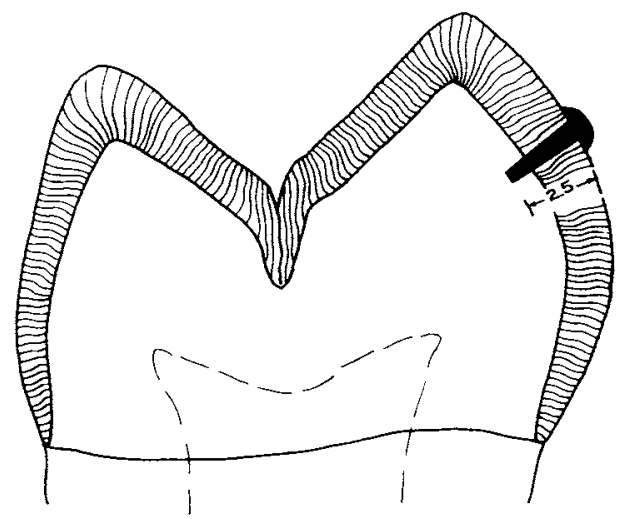

Fig 1.-Artificially prepared pit filled with sealant on the buccal surface of a mandibular molar. 


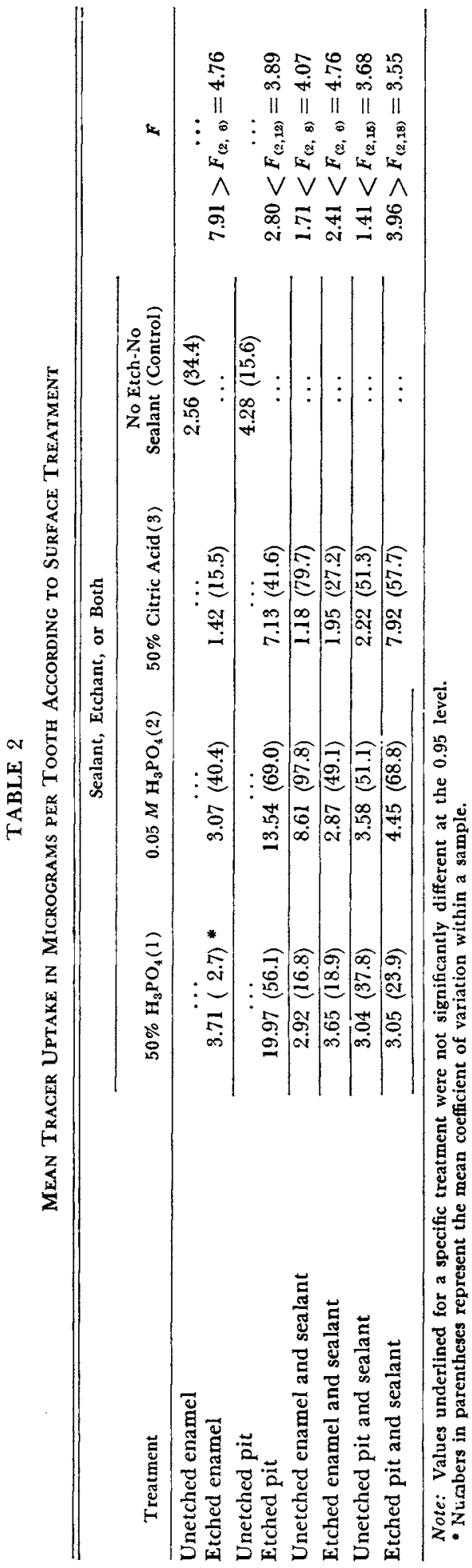

In Figure 2, the mean tracer uptake values are paired for unsealed and sealed conditions. Each pair corresponds to one of the four specimen groups studied for every sealant; that is, unetched and etched enamel and unetched and etched pit. Each pair of sealed and unsealed specimens was tested statistically for their least significant difference, ${ }^{7}$ and the pairs in which a significant difference was found are marked on the graph. Significant differences were found when material 2 was placed over unetched enamel or when either materials 1 or 2 were placed in an etched pit.

Since each sealant is to be used after the proper surface treatment, the etching procedures were tested on both polished enamel and the model pits. Analysis of variance and Duncan's new multiple range test for unequal replications were performed between the three etchant groups and for each of the two types of specimens (Table 2). Significantly less uptake was recorded through enamel when etched with $50 \%$ citric acid. No difference could be shown when the various etches were applied to the model pits. The efficiency of each of the three sealants was then compared for the four specimen treatments with analysis of variance and Duncan's test (Table 2). No significant difference in tracer uptake could be found among the three materials when they were applied to either etched or unetched enamel or to an unetched pit. There was significantly less uptake, however, around etched and sealed pits for materials 1 and 2 than for material 3.

After studying the influence of the etching procedure and the type of sealant on the tracer uptake of the two types of surfaces, an analysis was made of the influence of the specimen type and treatment on the sealing properties of a given sealant. Results of the analysis of variance and Duncan's test are given in Table 3 , and the mean coeffcient of variation for the four types of sealed specimens is reported as an indication of the ability of a sealant to produce equal performances under diverse conditions. There were no significant differences for either materials 1 or 2 under the four test conditions; however, material 3 showed a greater degree of leakage around an etched but sealed pit than around an unetched but sealed pit. 


\section{Discussion}

Results presented in Table 2 show high values for the coefficient of variation within each group of samples tested under a given surface condition. The neutron activation method used in this study was reported previously to have a coefficient of variation ranging between 15 and $30 \% .^{6}$ Individually tested conditions with a coefficient of variation below $40 \%$ can be accepted as normally dispersed results, especially with the small sample sizes used. Those conditions with a coefficient of variation higher than $40 \%$ indicate either an inconsistent capability of the sealer to inhibit leakage or defects present in the enamel of the extracted teeth. Each specimen group reported in Table 2 with a mean tracer uptake larger than that obtained for an unetched, unsealed pit (4.28 $\mu \mathrm{g})$ also has a coefficient of variation larger than $40 \%$. This seems to indicate that treatments (etching, sealing, or both) that result in greater tracer uptake also relate to an increase in dispersion of the results.

Unsealed but etched pits resulted in the highest uptake values for all three materials, but with correspondingly high coefficients of variation. The etching procedures possibly produce an uncontrolled opening of tubules and rods, leading to this significant increase in tracer uptake. The values reported in
Table 2 for unsealed but etched pits were not different significantly among the three materials, but they were in the same order as the values for etched enamel. Significantly lower uptake was present after enamel was etched with $50 \%$ citric acid than with either of the two phosphoric acid solutions.

The analysis of variance test indicates that there is no difference in uptake among the three sealants when they are placed over either etched or unetched enamel or in an unetched pit. There is a significant reduction in uptake when material 1 is placed in an etched pit (from 19.97 to $3.05 \mu \mathrm{g}$ ) (Fig 2). A similar reduction also takes place for material 2 (from 13.54 to $4.45 \mu \mathrm{g}$ ). Under comparative conditions, material 3 showed similar leakage for an etched pit, regardless of sealant placement. The citric acid etch seems to inhibit mechanical attachment of the material to create an enamel surface that facilitates leakage. Failure to seal unetched enamel with material 2 seems related to variables in handling the material, as evidenced by the large coefficient of variation.

Material 1 had the lowest overall coefficient of variation $(28 \%)$ among the three materials for the four groups of sealed specimens; all four values were less than $40 \%$ (Table 3). Materials 2 and 3 had higher values of $94 \%$ and $72 \%$, respectively, with
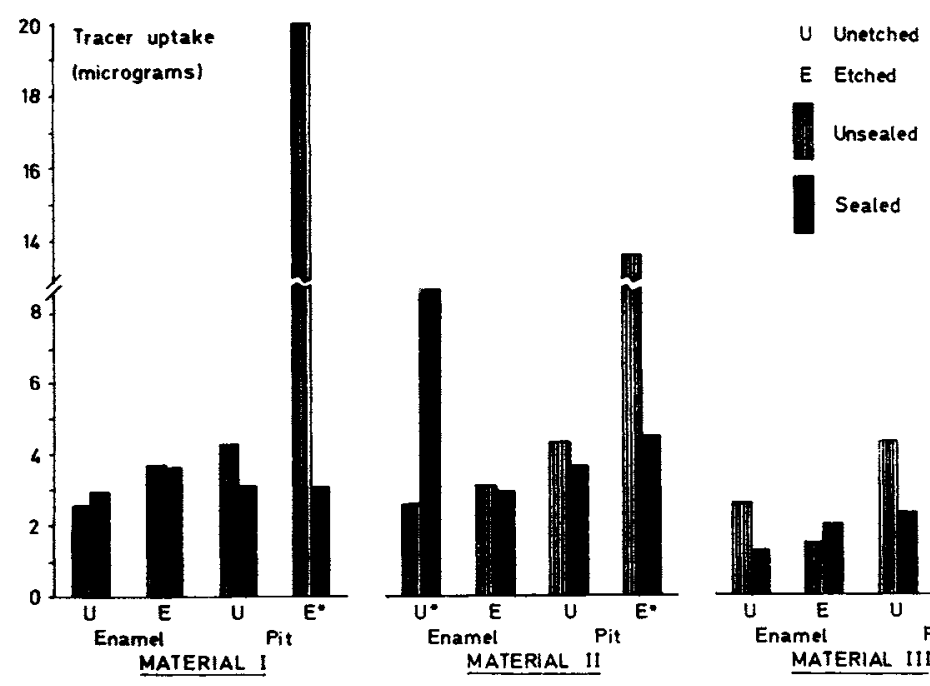

FIG 2,-Comparison of tracer uptake values for sealed and unsealed conditions. The two members of the pairs noted with an asterisk were significantly different. 
TABLE 3

Mean Tracer Uptake in Micrograms per Tooth According to Material

\begin{tabular}{lcccccc}
\hline \multicolumn{1}{c}{ Sealant } & $\begin{array}{c}\text { Coefficient } \\
\text { Variation }\end{array}$ & $\begin{array}{c}\text { Unetched } \\
\text { Enamel }\end{array}$ & $\begin{array}{c}\text { Etched } \\
\text { Enamel }\end{array}$ & $\begin{array}{c}\text { Unetched } \\
\text { Pit }\end{array}$ & $\begin{array}{c}\text { Etched } \\
\text { Pit }\end{array}$ & \multicolumn{1}{c}{ F } \\
\hline BIS-GMA & 28.1 & 2.92 & 3.65 & 3.04 & 3.05 & $0.45<F_{(3,16)}=3.34$ \\
$\alpha$-Cyanoacrylate & 93.8 & 8.61 & 2.86 & 3.57 & 4.45 & $\begin{array}{l}1.41<F_{(3,16)}=3.24 \\
\text { Polyurethane }\end{array}$ \\
\cline { 2 - 6 } & 71.7 & 1.18 & 1.95 & 2.22 & 7.92 & $6.10>F_{(3,17)}=3.20$ \\
\hline
\end{tabular}

Note: Values underlined were not significantly different at the 0.95 level.

all individual coefficient values but one being greater than $40 \%$. These results are at least an indication that material 1 tends to produce a more consistent type of seal with only minimal amounts of leakage.

The increased leakage resulting from etch ing deep pits could be sealed off with suitable efficiency by placing either materials 1 or 2 into the model pit, independent of the etching process (Table 3). Uptake values for material 1 were $3.04 \mu \mathrm{g}$ for an unetched pit and $3.05 \mu \mathrm{g}$ for an etched pit; whereas similar values of 3.57 and $4.45 \mu \mathrm{g}$, respectively were obtained for material 2 . On the other hand, material 3 reduced leakage when it was placed in an unetched pit $(2.22 \mu \mathrm{g})$, but it had little effect when the pit was etched $(7.92 \mu \mathrm{g})$. Thus etching seems to offer no advantage as far as initial seal is concerned with either the BIS-GMA resin or the cyanoacrylate materials; whereas it actually interferred with sealing when used with the polyurethane system.

It is not possible, from the results presented in this study, to conclude that the use of a sealant material truly prohibits leakage ( 0 uptake). Data does, however, indicate that the leakage that did occur under these controlled conditions was small and well within confidence limits for the means of the appropriate control specimens (2.56 $\mu \mathrm{g}$ for unetched enamel and $4.28 \mu \mathrm{g}$ for the unetched prepared model of a pit). This minimal degree of possible fluid exchange should be studied further under in vivo conditions to determine its clinical importance.

Use of a prepared model to simulate an anatomic pit seemed effective to control and to standardize the surface area covered during the experimental application of the sealant. Quantitative evaluation of the degree of leakage under these materials still showed a high degree of variation among samples, but this variation would have been much greater had the material been applied to the highly inconsistent morphology of an occlusal surface.

\section{Conclusions}

The BIS-GMA resin sealant, activated by ulrtaviolet light, produced the most consistent results when used in each of the four specimen treatments. The etching procedure with $50 \%$ phosphoric acid induced the highest tracer uptake in unsealed pits, probably resulting from attack on the dentin tubules and enamel rods. Sealing of the prepared model of a pit with material 1 was particularly effective, but use of the etch seemed to have no tendency to enhance the initial seal.

The $\alpha$-cyanoacrylate sealant had the greatest scattering of uptake values, as reflected by a high coefficient of variation for each condition. The etching procedure with 0.05 $M$ phosphoric acid produced a less severe attack of the dentin; this was shown by the tracer uptake value obtained on etched, but unsealed model pits. Placement of material 2 into a model pit also resulted in a significant decrease of the tracer uptake, which was independent of the etching process.

The polyurethane sealant generally showed lower tracer uptake values, although these differences were not statistically significant. Material 3 failed to reduce the tracer uptake when sealing the etched pits, but was, however, quite effective when placed in an unetched prepared pit. Therefore, the etching procedure has little effect in enhancing the initial seal with any of the three materials.

\section{References}

1. Arnold, F.A., Jr.; Dean, H.T.; JAY, P.; and Knutson, J.W.: Effect of Fluoridated Public Water Supplies on Dental Caries Prevalence, Tenth Year of the Grand Rapids-Muskegon 
Study, Public Health 71: 652-658, 1956.

2. Buonocore, M.G.: Adhesive Sealing of Pits and Fissures for Caries Prevention, With Use of Ultraviolet Light, JADA 80: 324, 1970.

3. Pugnier, V.A.: Cyanoacrylate Resins in Caries Prevention: A Two Year Study, JADA 84: 829-831, 1972.

4. LeE, H.L., and SwarTz, M.L.: Sealing of Developmental Pits and Fissures: I. In Vitro Study, J Dent Res 50: 133-140, 1971.

5. GoIng, R.E.; MYers, H.N.; and Prussin, S.G.:
Quantitative Method for Studying Microleakage In Vivo and In Vitro, J Dent Res 47: 1128 $1132,1968$.

6. MeYer, J.M.; Dennison, J.B.; and Craig, R.G.: Improved Neutron Activation Analysis Method for Microleakage Studies, abstracted, IADR Program and Abstracts of Papers, No. 24, 1973.

7. STEEL, R.G.D., and ToRrie, J.H.: Principles and Procedures of Statistics, New York: McGraw-Hill, 1960, p 114. 